\title{
Reply to the comment by C. K. Brooks and J. Gittins on my paper "Pseudoleucite from the Gardar of South Greenland"
}

\author{
S. P. HESSELBO
}

Department of Earth Sciences, University of Oxford, Parks Road, Oxford, OX1 3PR, U.K.

https://doi.org/10.37570/bgsd-1988-36-14

Brooks and Gittins make three main criticisms of my paper. The first, and perhaps the most important, is that they (Gittins et al. 1980) have already described and illustrated "all the textures described by Hesselbo and some additional ones". However, the four photomicrographs referred to (Gittins et al. 1980, p.121) are only of intergrowth sets from plutonic rocks and devoid of crystal outlines, which, by their own conclusions, should not actually be called pseudoleucite at all. In my paper, not only are the intergrowth textures from true icositetrahedral pseudoleucite clearly illustrated (from thin sections and a polished face), but also the relationships of these intergrowths to crystal faces, inclusions and cracks are described and discussed. Thus their contention that my descriptions and dicussion are largely redundant is entirely unjustified.

The other two complaints are of less importance. Of course, the estimation of lost alkalis is dependent on selecting six oxygens as the basis for calculation of elemental ratios, but there is by no means the degree of circularity about this procedure that Brooks and Gittins implied. The icositetrahedral form of the crystals, taken together with the gross similarity of the intergrowth textures to those of unaltered pseudoleucite, is sound enough evidence to assume leucite or anal- cite as the original mineral for the purposes of recalculation of the analyses. The near integer values for silicon and aluminium thus obtained are ample evidence that this initial selection was correct (Hesselbo 1986, p. 16).

My identification of cancrinite as an alteration product was necessarily speculative, and I am quite candid about this in the paper. In view of the fact that the optical observations are compatible with cancrinite, and that little is known about the XRD traces of K-rich cancrinite, "an interpretation of this mineral as K-rich cancrinite seems best with the limited information" (Hesselbo 1986, p. 13).

The aims of my paper were admittedly modest, but there is little of substance on Brooks and Gittins critique to justify their concluding statement.

\section{References}

Gittins, J., Fawcett, J. J., Brooks, C. K. \& Rucklidge, J. C. 1980: Intergrowth of nepheline - potassium feldspar and kalsilite - potassium feldspar: a re-examination of the "pseudo-leucite problem". Contrib. Mineral. Petrol. 73:119-126.

Hesselbo, S. P. 1986: Pseudoleucite from the Gardar of South Greenland. Bull. Geol. Soc. Denmark 35: 11-17. 